\title{
Solar Control: A general method for modelling of solar gains through complex facades in building simulation programs
}

For publication in Energy and Buildings

\author{
Tilmann E. Kuhn', Sebastian Herkel', Francesco Frontini' ${ }^{\prime+}$, \\ Paul Strachan"', Georgios Kokogiannakis"' \\ 'Fraunhofer Institute for Solar Energy Systems ISE, \\ Heidenhofstr. 2, 79110 Freiburg, Germany \\ Phone: +49-761/4588-5 297 Fax: +49-761/4588-9 297 \\ E-mail: tilmann.kuhn@ise.fraunhofer.de \\ http://www.ise.fraunhofer.de \\ " Politecnico di Milano, Dipartimento BEST \\ Via Bonardi 9 , 20133 Milano, Italy \\ '"' ESRU, Dept. of Mechanical Eng., University of Strathclyde \\ Glasgow G1 1XJ, UK. http://www.esru.strath.ac.uk
}

May 26, 2010 


\section{Contents}

1 Abstract 2

2 Introduction $\quad 3$

2.1 Solar Control - general statements . . . . . . . . . . . . . . . . . 3

2.2 Evaluation of complex facade components . . . . . . . . . . . . . . 4

3 The new method "black-box model" for building simulation programs 4

3.1 General . . . . . . . . . . . . . . . . . . . . . 4

3.2 Description of the model . . . . . . . . . . . . . . . . . . 6

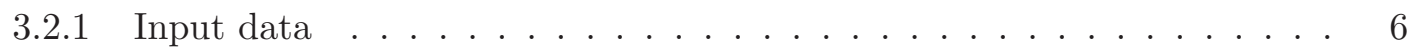

3.2.2 Modelling of the centre-of-glazing $U$-value . . . . . . . . . . . 6

3.2.3 Determination of the total solar absorptance $\alpha_{\mathrm{e}, \mathrm{tot}} \ldots \ldots \ldots \ldots$

3.2.4 Calculation of the absorptance in the two virtual layers . . . . . . . 8

3.2 .5 Treatment of diffuse irradiation . . . . . . . . . . . . . . . 9

3.2.6 Treatment of variable internal and external heat transfer coefficients . . 10

3.2.7 Treatment of thermal mass . . . . . . . . . . . . . . . . . . 11

3.2 .8 Treatment of back reflectance from the room . . . . . . . . . . . 12

3.3 Examples . . . . . . . . . . . . . . . . . . . . . 12 
3.3.1 Examples: External blinds . . . . . . . . . . . . . . . . 12

3.3.2 Examples: Internal blinds . . . . . . . . . . . . . . . . . 13

4 Implementation of the black-box model in ESP-r

4.1 Description of the implementation . . . . . . . . . . . . 14

4.2 Validation of the implementation . . . . . . . . . . . . . . . . 14

5 Assessment of the impact of the new model implemented in ESP-r 


\section{Nomenclature}

Angle definitions (numerical values of angles are specified in degrees throughout this publication):

$\gamma \quad$ facade orientation $\left(0^{\circ}:=\right.$ south, west positive $)$

$\gamma_{\mathrm{s}} \quad$ solar azimuth angle $\left(0^{\circ}:=\right.$ south, west positive $)$

$\gamma_{\mathrm{f}} \quad \gamma_{\mathrm{f}}:=\gamma_{\mathrm{s}}-\gamma\left(\right.$ facade azimuth angle, $0^{\circ}$ parallel to facade normal )

$\alpha_{\mathrm{s}} \quad$ solar altitude angle

$\alpha_{\mathrm{p}} \quad$ solar profile angle $\quad \alpha_{p}\left[\alpha_{s}, \gamma_{\mathrm{f}}\right]=\arctan \left(\frac{\tan \left(\alpha_{s}\right)}{\cos \left(\gamma_{\mathrm{f}}\right)}\right)[6]$

$\alpha_{\text {in }} \quad$ angle of incidence $\quad \alpha_{i n}\left[\alpha_{s}, \gamma_{\mathrm{f}}\right]=\arccos \left(\cos \left(\alpha_{s}\right) \cos \left(\gamma_{\mathrm{f}}\right)\right)[6]$

$\beta_{\mathrm{k}} \quad$ tilt angle of the slats of a venetian blind or - in the case of facades with switchable properties - a parameter field which characterises the switching state

Properties of glazing and blind:

$$
\begin{aligned}
& \mathcal{A}_{y, d, e z}^{x} \quad \mathcal{A}=[\tau / \rho / \alpha / g] \text { for } \\
& \text { [ transmittance / reflectance / absorptance / } g \text {-value (or TSET or Solar Factor) ] } \\
& \mathrm{x}=[\text { [ / nothing ] when [ radiation is incident on the inner surface / otherwise ] } \\
& \mathrm{y}=[e / v] \text { for }[\text { solar / light ] properties } \\
& \mathrm{d}=[\mathrm{dif} / \text { nothing }] \text { for [ diffuse irradiation / otherwise }] \\
& \mathrm{e}=[\text { eff-m / eff-h }] \text { for [ monthly / hourly ] effective (average) values } \\
& \mathrm{z}=[\mathrm{gzg} / \mathrm{bld} / \text { tot or nothing }] \text { for [glazing / blind / combination ] }
\end{aligned}
$$

Thermal resistances:

$U \quad U$-value

$R_{\mathrm{x}} \quad x=[e / i]$ for [ external / internal ] convective and radiative surface resistances and $[s]$ for the thermal resistance of the sample. $1 / U=R_{\mathrm{e}}+R_{\mathrm{S}}+R_{\mathrm{i}}$

Other: 


\section{Examples:}

$\rho_{v \text {, dif, gzg }}^{\prime}$ Diffuse light reflectance of the inner surface of glazing without blind

$\rho_{\text {gzg }}^{\prime}[\lambda] \quad$ Spectral reflectance of the inner surface of glazing without blind

$\alpha_{\text {tot }}\left[\alpha_{s}, \gamma_{\mathrm{f}}\right]$ Total absorptance in the facade

$g_{\text {tot }}\left[\alpha_{s}, \gamma_{\mathrm{f}}\right]$ Total Solar Energy Transmittance $g$ of glazing and blind

$g_{\mathrm{gzg}}\left[\alpha_{\mathrm{in}}\right] \quad$ Total Solar Energy Transmittance $g$ of glazing without blind

\section{Abstract}

This paper describes a new general method for building simulation programs which is intended to be used for the modelling of complex facades. The term 'complex facades' is used to designate facades with venetian blinds, prismatic layers, light re-directing surfaces etc. In all these cases, the facade properties have a complex angular dependence. In addition to this, such facades very often have non-airtight layers and/or imperfect components (e.g. non-ideal sharp edges, non-flat surfaces, ...). Therefore building planners often had to neglect some of the innovative features and to use 'work-arounds' in order to approximate the properties of complex facades in building simulation programs. A well-defined methodology for these cases was missing. This paper presents such a general methodology.

The main advantage of the new method is that it only uses measureable quantities of the transparent or translucent part of the facade as a whole. This is the main difference in comparison with state of the art modelling based on the characteristics of the individual subcomponents, which is often impossible due to non-existing heat- and/or light-transfer models within the complex facade.

It is shown that the new method can significantly increase the accuracy of heating/cooling loads and room temperatures. 


\section{Introduction}

\subsection{Solar Control - general statements}

Transparent components are essential to the design and performance of a building. They influence its indoor comfort and energy budget in many diverse ways: daylight illuminates indoor rooms throughout the year [1], solar energy can be used to heat buildings passively, excessive solar gains can cause glare and overheating. The amount of heat which enters modern buildings by conduction via opaque areas of the envelope is usually small due to the small temperature differences in summer and the level of thermal insulation which is already common in many countries. Conductive gains may still be relevant in warmer climates with less need for thermal insulation. For example, inadequately insulated roof areas in the older building stock present a main cause of solar gains in upper storeys: dark-coloured roofing materials are significant in increasing cooling loads in air-conditioned buildings during sunny summer days [29]. Dark-coloured facade claddings may also increase cooling loads especially in buildings with facade integrated openings for continuous ventilation. This paper concentrates on control of solar gains only; an overview of current work on glare protection for daylight conditions is given in [34]. The amount of transmitted heat, or solar gain, due to transparent areas of a building envelope is determined primarily by [28]:

- the size of the glazed areas

- the orientation of the glazed areas with respect to the sun

- external obstructions by surrounding buildings and trees

- the glazing properties

- the properties of sun-shading devices, and how they are operated. 


\subsection{Evaluation of complex facade components}

A combination of measurements and numerical models is the best choice for determining performances. Measurements are needed for validation. Modelling is needed in order to reduce the cost for the measurements by reducing the necessary number of measurements.

For the case of venetian blinds, the characterisation of glazing, blinds and combinations of glazing and blinds has been described in detail in [17] [18].

However, in many building simulation programs like for example [4], [8], [9] or [31] it is difficult to include the results of such facade measurements and facade simulations. A new solution to this problem is the topic of this paper.

\section{The new method "black-box model" for building simulation programs}

\subsection{General}

The general idea is to create an interface for building simulation programs (e.g. [4], [8], [9] or [31]) or which allows the properties of complex facades to be integrated without any modelling of the details within the building simulation program itself. The reasons for this approach are the following:

- There are always new facades which are too complex for the internal models which are included in the building simulation program itself. It is important for the success of new developments that the advantages of innovations can be demonstrated by building designers. The lack of an interface for these new products often slows down the market penetration of new daylighting and solar-control systems.

- In some cases, the thermal and optical properties of facades can not be described by 
models with sufficient accuracy. This is especially the case when the real component deviates significantly from the ideal design. An example could be a glazing unit with multiple integrated prismatic or light re-directing layers with imperfect edges and imperfect surface flatness of the light re-directing surfaces.

- Semi-empirical models have been developed for facades with venetian blinds which are able to describe the angle-dependent properties of the facade accurately, without needing too many (expensive) measurements [17]. However, to study the impact of such complex facades on overall building performance, it is necessary to integrate these models into a building simulation program.

Therefore a method was implemented in a whole building simulation program which requires only data which is measurable on the complete glazing unit. As input, the new method needs only the angle-dependent $g$-value/solar factor and solar transmittance of the total facade unit. If available, the solar reflectance $\rho_{e}$ (for solar radiation incident on the outer surface of the facade unit) can also be used as input, which improves the accuracy of modelling the external surface temperature. It is important to notice that it is not always necessary to measure $g$, $\tau_{e}$ and $\rho_{e}$ : in some cases these properties can be calculated with mathematical models, (for example, with the models given in [17] for the case of facades with venetian blinds).

The general idea of the model is to describe every complex facade with a two-layer model. Each of the two virtual layers has an effective solar absorptance with the desired angular dependence. Between the two layers, there is a temperature-dependent thermal resistance. This idea is quite similar to the ideas behind the $\gamma$-model which was developed by Rosenfeld [27] for the correction of non-standard boundary conditions during calorimetric $g$-value measurements. 


\subsection{Description of the model}

\subsubsection{Input data}

The starting point of the model is a set of measured or externally calculated values. Each data set $i$ is valid for different directions of the incident light and different settings of the control parameter $\beta_{\mathrm{k}}$. The model needs the following input:

- $g$-value $g_{\mathrm{tot}}\left[\alpha_{s, \mathrm{i}}, \gamma_{\mathrm{f}, \mathrm{i}}, \beta_{\mathrm{k}, \mathrm{i}}\right]$ (mandatory). In addition to the $g$-value, it is necessary to specify the thermal boundary conditions (surface resistances $R_{\mathrm{e}}$ and $R_{\mathrm{i}}$ ) which have been used for the determination of $g_{\text {tot }}$.

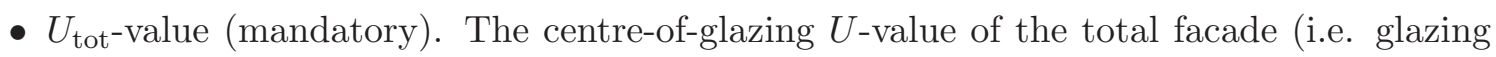
+ blind) is required for the same thermal boundary conditions as the $g$-value.

- Solar transmittance $\tau_{\mathrm{e}, \text { tot }}\left[\alpha_{s, \mathrm{i}}, \gamma_{\mathrm{f}, \mathrm{i}}, \beta_{\mathrm{k}, \mathrm{i}}\right]$ (mandatory).

- Solar reflectance $\rho_{\mathrm{e}, \text { tot }}\left[\alpha_{s, \mathrm{i}}, \gamma_{\mathrm{f}, \mathrm{i}}, \beta_{\mathrm{k}, \mathrm{i}}\right]$. (Optional. Needed only for accurate modelling of the temperature of the external surface, not needed for the correct modelling of the solar gains and the internal surface temperature.)

Instructions for using the new interface in ESP-r and a description of the data format for the new interface can be found in [12].

\subsubsection{Modelling of the centre-of-glazing $U$-value}

In general, the $U$-value of a facade depends on the difference between the exterior and the interior temperature and on the temperatures of the surfaces which exchange heat via thermal radiation heat transfer. The temperature difference is mainly responsible for the convection patterns. The radiative heat transfer can be approximated to be proportional to $T_{\text {mean }}^{3}$, where $T_{\text {mean }}$ is the mean temperature of the facade component in $K$ [6]. In most cases, the influence 
of the temperature difference is much smaller than the influence of the mean temperature of the sample. The influence of the temperature difference on the $U$-value is therefore neglected. The $U$-value of glazing typically increases with raising $T_{\text {mean }}$. It typically increases with rates between $0.3 \% / \mathrm{K}$ and $1 \% / \mathrm{K}$. We therefore approximate the sample $U$-value with

$$
U\left[T_{\text {mean }}\right]=U[283 K]\left(a_{0}+a_{1} T_{\text {mean }}+a_{2} T_{\text {mean }}^{2}+a_{3} T_{\text {mean }}^{3}\right)
$$

Therefore

$$
R_{\mathrm{s}}\left[T_{\text {mean }}\right]=U\left[T_{\text {mean }}\right]^{-1}-R_{\mathrm{e}}-R_{\mathrm{i}}
$$

\section{Special case: Unknown temperature dependence of centre-of-glazing $U$-value}

If the temperature dependence of the $U$-value for the centre of glazing is unknown, we use the following coefficients as an approximation (these are typical values for insulating glazing units with $U$-values around $\left.1.2 \mathrm{~W} /\left(\mathrm{m}^{2} K\right)\right)$ :

$$
\begin{aligned}
& a_{0}=-0.8395 \\
& a_{1}=0.0065 \\
& a_{2}=0 \\
& a_{3}=0
\end{aligned}
$$

\subsubsection{Determination of the total solar absorptance $\alpha_{\mathrm{e}, \text { tot }}$}

The total solar absorptance $\alpha_{\mathrm{e}, \text { tot }}$ is

$$
\alpha_{\mathrm{e}, \mathrm{tot}}\left[\alpha_{s, \mathrm{i}}, \gamma_{\mathrm{f}, \mathrm{i}}, \beta_{\mathrm{k}, \mathrm{i}}\right]=1-\tau_{\mathrm{e}, \mathrm{tot}}\left[\alpha_{s, \mathrm{i}}, \gamma_{\mathrm{f}, \mathrm{i}}, \beta_{\mathrm{k}, \mathrm{i}}\right]-\rho_{\mathrm{e}, \mathrm{tot}}\left[\alpha_{s, \mathrm{i}}, \gamma_{\mathrm{f}, \mathrm{i}}, \beta_{\mathrm{k}, \mathrm{i}}\right]
$$

\section{Special case: Unknown total reflectance}

In many cases, the total solar reflectance $\rho_{\mathrm{e}, \text { tot }}$ for radiation coming from outside is not known (no calculated or measured values available). In these cases, the total reflectance $\rho_{\mathrm{e}, \text { tot }}$ is 
estimated to be the mean value between the maximum possible physically meaningful value and the minimum possible physically meaningful value (which is zero):

$$
\rho_{\mathrm{e}, \mathrm{tot}}\left[\alpha_{s, \mathrm{i}}, \gamma_{\mathrm{f}, \mathrm{i}}, \beta_{\mathrm{k}, \mathrm{i}}\right] \approx 0.5\left(1-\tau_{\mathrm{e}, \operatorname{tot}}\left[\alpha_{s, \mathrm{i}}, \gamma_{\mathrm{f}, \mathrm{i}}, \beta_{\mathrm{k}, \mathrm{i}}\right]\right)
$$

which means that in this case

$$
\alpha_{\mathrm{e}, \mathrm{tot}}\left[\alpha_{s, \mathrm{i}}, \gamma_{\mathrm{f}, \mathrm{i}}, \beta_{\mathrm{k}, \mathrm{i}}\right] \approx 0.5\left(1-\tau_{\mathrm{e}, \text { tot }}\left[\alpha_{s, \mathrm{i}}, \gamma_{\mathrm{f}, \mathrm{i}}, \beta_{\mathrm{k}, \mathrm{i}}\right]\right)
$$

\subsubsection{Calculation of the absorptance in the two virtual layers}

The next step is the calculation of the absorptance in the two virtual layers. It is known (see e.g. [7]) that

$$
\begin{aligned}
q_{\mathrm{i}, \text { tot }}\left[\alpha_{s, \mathrm{i}}, \gamma_{\mathrm{f}, \mathrm{i}}, \beta_{\mathrm{k}, \mathrm{i}}\right] & :=g_{\mathrm{tot}}\left[\alpha_{s, \mathrm{i}}, \gamma_{\mathrm{f}, \mathrm{i}}, \beta_{\mathrm{k}, \mathrm{i}}\right]-\tau_{\mathrm{e}, \mathrm{tot}}\left[\alpha_{s, \mathrm{i}}, \gamma_{\mathrm{f}, \mathrm{i}}, \beta_{\mathrm{k}, \mathrm{i}}\right] \\
& =\frac{R_{\mathrm{e}}^{\star} \alpha_{\text {outer layer }}+\left(R_{\mathrm{e}}^{\star}+R_{\mathrm{s}}^{\star}\left[T_{\text {mean }}^{\star}\right]\right) \alpha_{\text {inner layer }}}{R_{\mathrm{e}}^{\star}+R_{\mathrm{s}}^{\star}\left[T_{\text {mean }}^{\star}\right]+R_{\mathrm{i}}^{\star}}
\end{aligned}
$$

where $T_{\text {mean }}^{\star}$ is the mean sample temperature during the determination of the $g$-value. $R_{\mathrm{x}}^{\star}$ are the specific surface thermal resistance values which have been used for the $g$-value and $U$-value determination. $\alpha_{\text {inner layer }}$ and $\alpha_{\text {outer layer }}$ are the virtual solar absorptance values in the inner and outer layer of the black box model. With

$$
\alpha_{\mathrm{e}, \text { tot }}\left[\alpha_{s, \mathrm{i}}, \gamma_{\mathrm{f}, \mathrm{i}}, \beta_{\mathrm{k}, \mathrm{i}}\right]=\alpha_{\text {inner layer }}\left[\alpha_{s, \mathrm{i}}, \gamma_{\mathrm{f}, \mathrm{i}}, \beta_{\mathrm{k}, \mathrm{i}}\right]+\alpha_{\text {outer layer }}\left[\alpha_{s, \mathrm{i}}, \gamma_{\mathrm{f}, \mathrm{i}}, \beta_{\mathrm{k}, \mathrm{i}}\right]
$$

we find

$$
\alpha_{\text {inner layer }}\left[\alpha_{s, \mathrm{i}}, \gamma_{\mathrm{f}, \mathrm{i}}, \beta_{\mathrm{k}, \mathrm{i}}\right]=\frac{q_{\mathrm{i}, \text { tot }}\left[\alpha_{s, \mathrm{i}}, \gamma_{\mathrm{f}, \mathrm{i}}, \beta_{\mathrm{k}, \mathrm{i}}\right]\left(R_{\mathrm{e}}^{\star}+R_{\mathrm{s}}^{\star}\left[T_{\text {mean }}^{\star}\right]+R_{\mathrm{i}}^{\star}\right)-\alpha_{\mathrm{e}, \text { tot }}\left[\alpha_{s, \mathrm{i}}, \gamma_{\mathrm{f}, \mathrm{i}}, \beta_{\mathrm{k}, \mathrm{i}}\right] R_{\mathrm{e}}^{\star}}{R_{\mathrm{s}}^{\star}\left[T_{\text {mean }}^{\star}\right]}
$$

and

$$
\begin{aligned}
& \alpha_{\text {outer layer }}\left[\alpha_{s, \mathrm{i}}, \gamma_{\mathrm{f}, \mathrm{i}}, \beta_{\mathrm{k}, \mathrm{i}}\right]= \\
& \frac{\alpha_{\mathrm{e}, \text { tot }}\left[\alpha_{s, \mathrm{i}}, \gamma_{\mathrm{f}, \mathrm{i}}, \beta_{\mathrm{k}, \mathrm{i}}\right]\left(R_{\mathrm{e}}^{\star}+R_{\mathrm{s}}^{\star}\left[T_{\text {mean }}^{\star}\right]\right)-q_{\mathrm{i}, \text { tot }}\left[\alpha_{s, \mathrm{i}}, \gamma_{\mathrm{f}, \mathrm{i}}, \beta_{\mathrm{k}, \mathrm{i}}\right]\left(R_{\mathrm{e}}^{\star}+R_{\mathrm{s}}^{\star}\left[T_{\text {mean }}^{\star}\right]+R_{\mathrm{i}}^{\star}\right)}{R_{\mathrm{s}}^{\star}\left[T_{\text {mean }}^{\star}\right]}
\end{aligned}
$$




\subsubsection{Treatment of diffuse irradiation}

It is well known that the diffuse irradiation is very significant for the solar gains and that the angular dependence has to be considered for the calculation of the solar gains caused by diffuse irradiation [16]. In [16] and [17], the diffuse sky is divided into 145 discrete sky patches according to [33] and the ground is divided into 5 different rings with constant radiance. This procedure leads to very accurate modelling of the solar gains. This procedure could also be implemented in building simulation programs.

A simpler approach is to divide the diffuse irradiation into two components, one coming from the upper half of the hemisphere (in most cases above the horizon), the other being reflected from the ground (the lower half of the hemisphere). It is shown in section 5, for the case of venetian blinds, that it is necessary to treat these two components of the diffuse irradiation seperately, rather than assuming isotropic diffuse irradiation. This statement can also be proven heuristically for the case of an external venetian blind with matt silver slats without glazing: from the formulae given in [17], the solar transmittance for the upper half of the hemisphere can be deduced to be:

$$
\begin{array}{rlrl}
\mathcal{A}_{y, \text { dif upper hem. }} & \approx b_{0} \mathcal{A}_{y}[0]+2 \sum_{k=1}^{6} b_{k} \mathcal{A}_{y}[15 k] & \\
b_{0} & =0.1304 & & b_{4}=0.0653 \\
b_{1} & =0.1261 & & b_{5}=0.0338 \\
b_{2} & =0.1130 & & b_{6}=0.0043 \\
b_{3} & =0.0923 &
\end{array}
$$

where $\mathcal{A}_{y}\left[\alpha_{p}\right]$ is the solar transmittance $\tau_{e}\left[\alpha_{p}\right]$ as a function of the profile angle in this case. The formula is valid for all facade systems with properties which are symmetric with respect to profile angle. The diffuse properties for the lower half of the hemisphere can be calculated 
analogously:

$$
\mathcal{A}_{y, \text { dif lower hem. }} \approx b_{0} \mathcal{A}_{y}[0]+2 \sum_{k=1}^{6} b_{k} \mathcal{A}_{y}[-15 k]
$$

In figure 1, the solar transmittance values for the upper and the lower halves of the hemisphere are shown for different tilt angles of the slats together with the total diffuse-hemispherical solar transmittance. It can be seen that the values for the upper half of the hemisphere are significantly lower than the values for the lower half of the hemisphere and the total values when the slats are tilted more than $10^{\circ}$ against a horizontal plane.

Figure 1 should be inserted here.

\section{General rules for the calculation of diffuse properties}

In general, the diffuse-hemispherical properties of facade systems $\mathcal{A}_{y \text {,dif }}$ can be calculated in the co-ordinate system $\left[\alpha_{s}, \gamma_{f}\right]$ with equation (16) given in [17]:

$$
\mathcal{A}_{y, \text { dif }}:=\frac{1}{\pi} \int_{-\frac{\pi}{2}}^{\frac{\pi}{2}} \int_{-\frac{\pi}{2}}^{\frac{\pi}{2}} \mathcal{A}_{y}\left[\alpha_{s} \frac{\pi}{180}, \gamma_{\mathrm{f}} \frac{\pi}{180}\right] \cos \left(\alpha_{s}\right)^{2} \cos \left(\gamma_{\mathrm{f}}\right) d \gamma_{\mathrm{f}} d \alpha_{s}
$$

where $\alpha_{s}$ and $\gamma_{\mathrm{f}}$ are expressed in degrees. Therefore

$$
\mathcal{A}_{y, \text { dif lower hem. }}:=\frac{2}{\pi} \int_{-\frac{\pi}{2}}^{0} \int_{-\frac{\pi}{2}}^{\frac{\pi}{2}} \mathcal{A}_{y}\left[\alpha_{s} \frac{\pi}{180}, \gamma_{\mathrm{f}} \frac{\pi}{180}\left[\cos \left(\alpha_{s}\right)^{2} \cos \left(\gamma_{\mathrm{f}}\right) d \gamma_{\mathrm{f}} d \alpha_{s}\right.\right.
$$

and

$$
\mathcal{A}_{y, \text { dif upper hem. }}:=\frac{2}{\pi} \int_{0}^{\frac{\pi}{2}} \int_{-\frac{\pi}{2}}^{\frac{\pi}{2}} \mathcal{A}_{y}\left[\alpha_{s} \frac{\pi}{180}, \gamma_{\mathrm{f}} \frac{\pi}{180}\right] \cos \left(\alpha_{s}\right)^{2} \cos \left(\gamma_{\mathrm{f}}\right) d \gamma_{\mathrm{f}} d \alpha_{s}
$$

\subsubsection{Treatment of variable internal and external heat transfer coefficients}

The $g$-value varies according to the thermal boundary conditions, especially according to the heat transfer coefficients $h_{e}$ and $h_{i}$. For example: the higher the wind speed, the higher is 
the external heat transfer coefficient $h_{e}$. This leads to more effective transfer of the absorbed energy $\alpha_{\mathrm{e}, \text { tot }}$ to the outside and therefore results in a lower $g$-value.

This effect is taken into account in the new black box model since the values for the solar

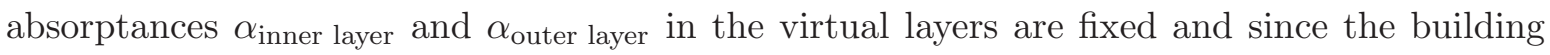
simulation program calculates $R_{e}$ and $R_{i}$ for every time-step according to the meteorological input data for the location under examination.

\subsubsection{Treatment of thermal mass}

Two aspects of the thermal mass have to be taken into account in the black-box model:

- The total thermal mass

- The distribution of the thermal mass between the two virtual layers.

To assess the effect, the following cases have been compared:

- equal distribution of the typical thermal mass of a double-glazed unit ( $6 \mathrm{~mm}$ glass panes) between the two virtual layers in the black-box model.

- $96 \%$ of the total mass of case 1 concentrated in the outer virtual layer.

- $96 \%$ of the total mass of case 1 concentrated in the inner virtual layer.

The details of this evaluation are described in [11]. The results are the following: The average difference between the first case and last two cases was less than $0.05 \mathrm{~K}$. It is therefore assumed that we can neglect this effect. 


\subsubsection{Treatment of back reflectance from the room}

Since the black-box model uses effective absorptance values for each virtual layer, there is no change necessary in the building simulation programs for the internal treatment of back reflectance from the room. For the case of ESP-r, this means that the reflections from the room are correctly taken into account according to the descriptions in [30].

\subsection{Examples}

The angle-dependent properties of facades are the starting point for the calculation of the facade properties which are used as input for the black-box model (see section 3.2.1). The angle-dependent properties of facades can be either measured or calculated. For facades with venetian blinds, they can be calculated with the equations given in [17].

\subsubsection{Examples: External blinds}

As an example for external blinds, a venetian blind with convex matt silver slats is used. The near-normal-hemispherical solar reflectance of the surfaces of the slats is $\rho_{\mathrm{e}, \mathrm{n}-\mathrm{h}}=0.51$. The near-normal-diffuse solar reflectance of the surfaces of the slats is $\rho_{\mathrm{e}, \mathrm{n} \text {-dif }}=0.47$. For the definition of the surface properties of the slats and the conditions for the reflectance measurements, see the European Standard EN14500 [10], to which the first author of this paper has contributed. The slats have additional small curved rims at the edges of the slats in order to increase their mechanical stability. Therefore the thickness of the slats is not negligible. This venetian blind (with small variations in the type of the matt silver colour of the slats) is the most common venetian blind in Germany, Switzerland and Austria. It has also been used for the assessments in [11]. In this example, the venetian blind has been combined with low-e glazing with $g_{\mathrm{gzg}}=0.58, \tau_{\mathrm{e}, \mathrm{gzg}}=0.51$ and $\tau_{\mathrm{v}, \mathrm{gzg}}=0.75$. The angle-dependent $g$-value and solar transmittance $\tau_{e}$ of this facade are shown in figures 2 and 3 . They have been calculated with the equations given in [17]. The angle-dependent total solar absorptance has 
been calculated for the special case of unknown reflectance. The results are shown in figure 4. From the total absorptance, the solar absorptances in the two virtual layers have been calculated for the boundary conditions of $R_{e}=\left(23 W /\left(m^{2} K\right)\right)^{-1}, R_{i}=\left(8 W /\left(m^{2} K\right)\right)^{-1}$ and a $U$-value for the centre of glazing of $1.2 \mathrm{~W} /\left(\mathrm{m}^{2} \mathrm{~K}\right) . \alpha_{\text {inner layer }}$ and $\alpha_{\text {outer layer }}$ for the two virtual layers are shown in figures 5 and 6 .

Figures 2 - 6 should be inserted here.

\subsubsection{Examples: Internal blinds}

The characterisation of facades with internal blinds has been discussed extensively in section 2.5.1. of [17] and in [18]. In this section, an internal Genius blind (for details see [18]) in combination with solar-control glazing with $g_{\mathrm{gzg}}\left[0^{\circ}\right]=0.31$ is used as an example. The same combination has also been used in [18] and [11] as an example. Equations (21)-(24) from [17] were used for the calculation of the facade properties. The validation of these formulae is documented in table 4 and table 5 in [17]. The $g$-value $g_{\text {tot }}$ and the solar transmittance $\tau_{\text {e,tot }}$ are shown in figures 7 and 8 .

In addition to the formulae given in [17], a new formula for the calculation of the solar reflectance $\rho_{\mathrm{e}, \text { tot }}$ was used:

$$
\begin{aligned}
\rho_{\mathrm{e}, \mathrm{tot}}\left[\alpha_{s}, \gamma_{\mathrm{f}}, \beta_{\mathrm{k}}\right]= & \rho_{\mathrm{e}, \mathrm{gzg}}\left[\alpha_{i n}\left[\alpha_{s}, \gamma_{\mathrm{f}}\right]\right] \\
& +\tau_{\mathrm{e}, \mathrm{gzg}}\left[\alpha_{i n}\left[\alpha_{s}, \gamma_{\mathrm{f}}\right]\right] \tau_{x^{\star}, \operatorname{dif}, \mathrm{gzg}} \frac{\rho_{x^{\star}, \mathrm{bld}}\left[\alpha_{p}\left[\alpha_{s}, \gamma_{\mathrm{f}}\right], \beta_{\mathrm{k}}\right]}{1-\rho_{x^{\star}, \operatorname{dif}, \mathrm{bld}}\left[\beta_{\mathrm{k}}\right] \rho_{x^{\star}, \mathrm{dif}, \mathrm{gzg}}^{\prime}}
\end{aligned}
$$

The angle-dependent total solar absorptance was calculated for the case of known reflectance with equation 4 . The results are shown in figure 9. It should be noted that the total solar absorptance decreases for the situations where the venetian blind has a high transmittance. This means that more light is being transmitted directly instead of being absorbed in the blind. The solar absorptance in the two virtual layers has been calculated from the total absorptance for the boundary conditions of $R_{e}=\left(23 W /\left(m^{2} K\right)\right)^{-1}, R_{i}=\left(8 W /\left(m^{2} K\right)\right)^{-1}$ and 
a $U$-value of the centre of glazing of the facade of $1.1 \mathrm{~W} /\left(\mathrm{m}^{2} \mathrm{~K}\right) \cdot \alpha_{\text {inner layer }}$ and $\alpha_{\text {outer layer }}$ for the two virtual layers are shown in figure 10 and 11.

Figures 7 - 11 should be inserted here.

\section{Implementation of the black-box model in ESP-r}

\subsection{Description of the implementation}

The implementation is described in detail in [12].

\subsection{Validation of the implementation}

The correct implementation in ESP-r has been checked with a simple case that can be calculated correctly also with the existing models in ESP-r [11]. For this purpose, a double-glazed unit(DGU) with a low-e coating on the outer surface of the inner pane was chosen. Glazing properties: $g_{\mathrm{gzg}}=0.58, \tau_{\mathrm{v}, \mathrm{gzg}}=0.75$ and $\mathrm{U}$-value $=1.0 \mathrm{~W} /\left(\mathrm{m}^{2} K\right)$. The results for the new black-box model and the existing model were practically identical: the average difference between the results for the operative temperatures of the two models was $0.09 \mathrm{~K}$, the maximum difference was always less than $0.2 \mathrm{~K}$ (for details see [11]). Other checks, for both isotropic and non-isotropic glazing, were also carried out to ensure that the calculations of the virtual layer absorptances and the sky and ground reflected diffuse transmittances and absorptances were calculated correctly. It was concluded that the model has been implemented correctly. 


\section{Assessment of the impact of the new model implemented in ESP-r}

In [17] it was shown that the solar gains through facades can be incorrect when the wrong angular dependence of the g-value is used. In [17], the author specifically assessed the difference between the assumption of properties with profile angle symmetry and rotationally symmetric properties. However, the effect on the results of building simulations were not assessed in [17]. This has now been done using the new black-box model implemented in ESP-r. The details are given in [11]. In [11], the operative temperature, the heating loads and the cooling loads of an office-room were analysed for the two different cases of angular dependence. The different angular symmetries for $g_{\text {tot }}$ are illustrated in detail in figure 12 of [17]. In [11] these effects were analysed for four different blinds (matt silver venetian blind, venetian blind with Genius

slats, stainless steel blind and 'daylighting' venetian blind with mirror-finished top surface of the slats). We combined these venetian blinds with three different facade types (completely glazed (transparent area $90 \%$ ), large horizontal window (transparent area $35 \%$ ) and single window (transparent area $22 \%$ ). For the room model, a typical office configuration in the main building of Fraunhofer ISE was used. It has a medium-heavy construction consisting of light-weight internal walls but concrete floor, ceiling and external walls. The external walls have a $U$-value of $U=0.18 \mathrm{~W} /\left(\mathrm{m}^{2} \mathrm{~K}\right)$. The real building uses passive cooling techniques: a special night-ventilation system without any mechanical cooling is used in this building. For the sake of simplicity and easy comparison with other buildings, the passive cooling was not taken into account. Only the cases with and without a mechanical cooling system were assessed. An evaluation of the real Fraunhofer ISE building can be found in [23]. An analysis was carried out with the building located in Freiburg (Germany), Stockholm (Sweden) and Milan (Italy) with facade orientations of south, south-west, and west. The intention was to quantify the impact of the black-box model and the use of the correct angular dependent facade properties for the case of a realistic building. More details are given in [11]. Only the main conclusions and results are given here. The main result is that it is very important to use the correct angular dependence in building simulations: 
- For a fully glazed, south-facing facade in Freiburg, Germany with an external venetian blind with matt-silver slats, it was found that the wrong assumption of rotationally symmetric angular dependence leads to an underestimation of the total summer cooling load by $47 \%$ in the case of a mechanically cooled building. The underestimations of the total cooling load for the same building at the locations Milan and Stockholm are $-55 \%$ and $-99 \%$ respectively [11].

- For the same cases (but without a cooling system and with a west-facing instead of a south-facing facade), the assumption of the wrong rotationally symmetric properties leads to an underestimation of the average temperature by more than $2.5 \mathrm{~K}$ and an underestimation of the maximum temperature by up to $5.2 K[11]$.

- The heating energy demand is generally overestimated when the incorrect rotationally symmetric angular dependence is used. The relative overestimation of the heating demand for Freiburg, Milan and Stockholm is 17\%, $23 \%$ and $20 \%$ respectively [11].

These results highlight the improvements that can be achieved with the new interface for ESP-r. The application of the new black-box model is by no means limited to venetian blinds. There are many other types of complex glazing on the market which can now be modelled accurately in ESP-r. The roof glazing of the German Museum 'Haus der Geschichte' (which contains metallic light-redirecting structures in order to transmit only the diffuse irradiation from the northern part of the sky) can be considered as an example for this type. For other examples see section 3.1.

\section{Conclusion}

A new method for integrating complex facades in building simulation programs has been described in detail. The method is designed to be used for complex facade components with non-trivial angular dependence. All these complex components can be treated in the same simple way: 
- Measure $g_{\mathrm{tot}}, \tau_{\mathrm{e}, \text { tot }}$ and preferably also $\rho_{\mathrm{e}, \text { tot }}$ for different directions of the incident radiation. If possible/applicable, the number of necessary measurements can be reduced when the data points can be interpolated with a sufficiently accurate physical model.

- Create an input file with these data for ESP-r.

- Run the building simulations.

The method has been implemented in ESP-r and the implementation has been validated. It should be easy to implement the method in other detailed simulation programs such as [9], [8], [31] or [32]. It was shown that there are practically relevant cases in which the new method can help to significantly increase the accuracy of determining the heating and cooling loads and the room temperatures. It was shown that the error of conventional simulation techniques can be quite large $(55 \%$ underestimation of the cooling load in Milan is possible when the wrong angular dependence is used).

\section{Acknowledgements}

This work has been co-funded by the Velux Stiftung, Switzerland under the contract number 248. 


\section{References}

[1] O. Aschehoug, S. Aydinli, J. Christoffersen, G. Courret, I. Edmonds, R. Jakobiak, M. Kischkoweit-Lopin, M. Klinger, E. Lee, L. Michel, J.-L. Scartezzini, S. Selkowitz, (ed.): Daylight in Buildings, IEA SHC Task 21/ECBCS Annex 29. LBNL Report Number: LBNL-47493. http://gaia.lbl.gov/iea21/

[2] K. Blümel, E. Hollan, A. Jahn, M. Kähler, R. Peter, Entwicklung von Testreferenzjahren (TRY) für die Klimaregionen der Bundesrepublik Deutschland. Scientific report of the Institute for Geophysical Sciences Technical University Berlin. BMFT-FB-T- 86-051, July 1986.

[3] C. Bühler, Mikrostrukturen zur Steuerung von Tageslichtströmen, Inaugural-Dissertation zur Erlangung des Doktorgrades der Fakultät für Mathematik und Physik der AlbertLudwigs-Universität Freiburg, (PHD-Thesis), May 2003.

[4] J. Clarke, Energy Simulation in Buiding Design, second ed., Butterworth-Heinemann, 2001.

[5] A. Dama, Angular dependency of optical properties and energy performances of glazing and solar shading devices for windows and facades, Politecnico di Milano, Dipartimento di Energetica, Dottorato di Ricerca in Energetica XVI ciclo (this PHD-thesis has been prepared in co-operation with Fraunhofer ISE, Freiburg Germany), Milan, Italy, Anno Accademico 2003-2004.

[6] J. A. Duffie, W. A. Beckman, Solar Engineering of Thermal Processes Wiley-Interscience Publication, 1991.

[7] DIN EN 410 Bestimmung der lichttechnischen und strahlungsphysikalischen Kenngrößen von Verglasungen. Glass in Building - Determination of luminous and solar characteristics of glazing. German Version EN 410: 1998. (This standard replaces DIN67507: 1980-06). 
[8] DOE-2 is a widely used and accepted building energy analysis program that can predict the energy use and cost for all types of buildings, http://www.doe2.com/.

[9] EnergyPlus, U.S. Department of Energy, EnergyPlus Energy Simulation Software, http://apps1.eere.energy.gov/buildings/energyplus/

[10] EN 14500 Blinds and shutters - Thermal and visual comfort - Test and calculation methods, European Standard, May 2008.

[11] F. Frontini, S. Herkel, T. E. Kuhn, Evaluation of a new method for solar control calculation in the ESP-r building simulation program, submitted for publication to Energy and Buildings, 2009.

[12] F. Frontini, S. Herkel, T. E. Kuhn, P. Strachan, G. Kokogiannakis, Implementation of a new bi-directional solar modelling method for complex facades within the ESP-r building simulation program and its application, conference paper IBPSA Building Simulation 2009, University of Strathclyde, Glasgow, Scotland, 27th - 30th July 2009.

[13] ISO 9050: Glass in Building - Determination of light transmittance, solar direct transmittance, total solar energy transmittance, ultraviolet transmittance and realated glazing factors, International Organisation for Standardisation, Geneve, Switzerland, 1990.

[14] ISO 15099 Thermal performance of windows, doors and shading devices - Detailed calculations, International Organisation for Standardisation, Geneve, Switzerland, November 2003.

[15] J. Karlsson, A. Roos, Modelling the angular behaviour of the total solar energy transmittance of windows, Solar Energy, 69, 4 (2000).

[16] T. E. Kuhn, C. Bühler, W. J. Platzer Evaluation of overheating protection with sunshading systems, Solar Energy Vol.69 (Suppl.) Nos. 1-6, pp. 59-74, 2000.

[17] T. E. Kuhn, Solar control: A general evaluation method for facades with venetian blinds or other solar control systems to be used 'stand-alone' or within building sim- 
ulation programs, Energy and Buildings, Vol 38, Issue 6, pp. 648-660, June 2006. http://dx.doi.org/10.1016/j.enbuild.2005.10.002

[18] T. E. Kuhn, Solar control: Comparison of two new systems with the state of the art on the basis of a new general evaluation method for facades with venetian blinds or other solar control systems, Energy and Buildings, Vol 38, Issue 6, pp. 661-672, June 2006. http://dx.doi.org/10.1016/j.enbuild.2005.10.001.

[19] T. E. Kuhn, Sonnenschutz: Eine generelle Bewertungsmethode - auch für zwischenliegende Systeme - und zwei neue Behänge, Bauphysik, Vol 29 (2007), Heft 1, pp. 63-71, 2007. http://dx.doi.org/10.1002/bapi.200710012

[20] OPTICAD Optical Analysis Program, Opticad Corporation, 511 Juniper Drive, Santa Fe (NM), 87501 USA.

[21] R. Perez, P. Ineichen, R. Seals, J. Michalsky, R. Stewart, Modeling of daylight availability and irradiance components from direct and global irradiance, Solar Energy 44 (5) (1990) 271-289.

[22] R. Perez, R. Seals, J. Michalsky, All-weather model for sky luminance distribution - preliminary configuration and validation, Solar Energy 50 (3) (1993) 235-245.

[23] J. Pfafferott, Enhancing the Design and Operation of Passive Cooling Concepts. Fraunhofer IRB Verlag, Stuttgart, 2004.

[24] W. J. Platzer, Energetische Bewertung von Transparenter Wärmedämmung Fraunhofer ISE Study TOS4-WJP-9705-E01, June 1997.

[25] C. Reinhart, O. Walkenhorst, Dynamic RADIANCE-based Daylight Simulations for a full-scale Test Office with outer Venetian Blinds, Energy and Buildings 32 (2000) 167187.

[26] A. Roos, J. Karlsson, P. A. van Nijnatten, M. G. Hutchins, P. Polato, E. Nichelatti, M. Montecchi, F. Olive, C. Anderson, Angular dependent optical properties of coated glazings - validation of two predictive algorithms, SPIE-Conference. 
[27] J.L.J. Rosenfeld, Proc. of the 8th International Meeting on Transparent Insulation Material, Freiburg, Germany, 1996. It is difficult to get the paper, therefore it has been put with the permission of the author on the Fraunhofer ISE web-site: http://www.ise.fraunhofer.de/downloads/pdf-files/paper/paper-rosenfeld

[28] M. Santamouris (Editor) and Nicol F., Roaf S., Akbari H., Voss K., Kuhn T. E., Nitz P., Herkel S., Wall M., Hellström B., Kolokotroni M., Pfafferott J., Walker-Hertkorn S., Sanner B. and Erell E., Advances in passive cooling, Earthscan, August 2007, 284 pages, ISBN: 9781844072637

[29] Simpson, J. R., McPherson, E. G., The effects of roof albedo modification on cooling loads of scale model residence in Tucson, Arizona, Energy and Buildings, 25 (2), pages 127-137, 1997

[30] P. Strachan, Addition of Blind/Shutter Control to Transparent Multi-Layer Constructions and Other Improvements to the Solar Routines of ESPsim, ESRU Occasional Paper, available online as http://www.esru.strath.ac.uk/Documents/90/strachan_solar_mods.pdf

[31] TRNSYS The Transient Energy System Simulation Tool, http://www.trnsys.com/

[32] TAS Thermal Analysis Software, http://www.harvardthermal.com/

[33] P. Tregenza, Subdivision of the sky hemisphere for luminance measurements, Light. Res. Technol. 19 (1987) 13-14.

[34] Wienold, J., Christoffersen, J.: Evaluation methods and development of a new glare protection model for daylight environments with the use of CCD cameras, Energy and Buildings, vol. 38 (2006), p. 743-757. 


\section{List of Tables}




\section{List of Figures}

1 Diffuse transmittance for an external venetian blind with convex (conventionally shaped) slats without glazing. The top surface of the slats is matt silver $\left(\rho_{\mathrm{e}, \text { tot }}=\right.$ $0.59)$, the bottom is light grey $\left(\rho_{\mathrm{e}, \mathrm{tot}}=0.58\right) \ldots \ldots \ldots \ldots \ldots$

$2 g$-value for an external, matt silver venetian blind with convex (conventionally shaped) slats in combination with glazing with $g_{\mathrm{gzg}}=0.58$. The line graphs on the right hand side are valid for $\gamma_{f}=0 \ldots \ldots \ldots$

3 Solar transmittance $\tau_{e}$ for an external, matt silver venetian blind with convex (conventionally shaped) slats in combination with a glazing with $g_{\mathrm{gzg}}=0.58$. The line graphs on the right hand side are valid for $\gamma_{\mathrm{f}}=0 \ldots \ldots \ldots$

4 Angle-dependent total solar absorptance $\alpha_{\mathrm{e}, \text { tot }}$ in the facade for an external, matt silver venetian blind with convex (conventionally shaped) slats in combination with glazing with $g_{\mathrm{gzg}}=0.58$. $\alpha_{\mathrm{e}, \text { tot }}$ has been calculated for the special case of unknown reflectance $\rho_{\mathrm{e}, \text { tot }}$. The line graphs on the right hand side are

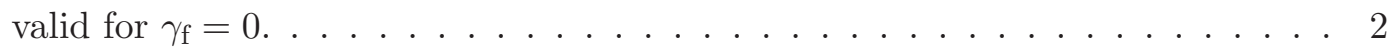

5 Angle-dependent solar absorptance $\alpha_{\text {inner layer }}$ in the facade for an external, matt silver venetian blind with convex (conventionally shaped) slats in combination with glazing with $g_{\mathrm{gzg}}=0.58$. $\alpha_{\text {inner layer }}$ has been calculated for the special case of unknown reflectance $\rho_{\mathrm{e}, \text { tot }}$. The line graphs on the right hand

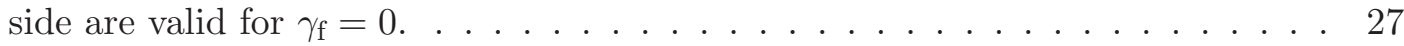

6 Angle-dependent solar absorptance $\alpha_{\text {outer layer }}$ in the facade for an external, matt silver venetian blind with convex (conventionally shaped) slats in combination with glazing with $g_{\mathrm{gzg}}=0.58$. $\alpha_{\text {outer layer }}$ has been calculated for the special case of unknown reflectance $\rho_{\mathrm{e}, \mathrm{tot}}$. The line graphs on the right hand side are valid for $\gamma_{\mathrm{f}}=0 \ldots \ldots \ldots \ldots \ldots \ldots$ 
$g$-value for an internal venetian blind with Genius slats in combination with glazing with $g_{\mathrm{gzg}}=0.31$. The line graphs on the right hand side are valid for

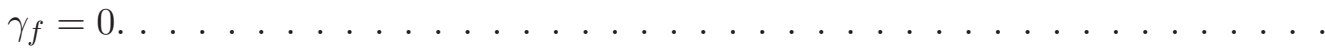

8 Solar transmittance $\tau_{e}$ for an internal venetian blind with Genius slats in combination with glazing with $g_{\mathrm{gzg}}=0.31$. The line graphs on the right hand side

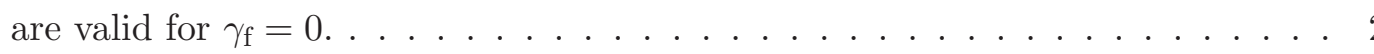

9 Angle-dependent total solar absorptance $\alpha_{\mathrm{e}, \text { tot }}$ in the facade for an internal venetian blind with Genius slats in combination with glazing with $g_{\mathrm{gzg}}=0.31$. $\alpha_{\mathrm{e}, \text { tot }}$ has been calculated for the case of known reflectance $\rho_{\mathrm{e}, \mathrm{tot}}$. The line graphs on the right hand side are valid for $\gamma_{\mathrm{f}}=0 \ldots \ldots \ldots$

10 Angle-dependent solar absorptance $\alpha_{\text {inner layer in the facade for an internal vene- }}$ tian blind with Genius slats in combination with glazing with $g_{\mathrm{gzg}}=0.31$.

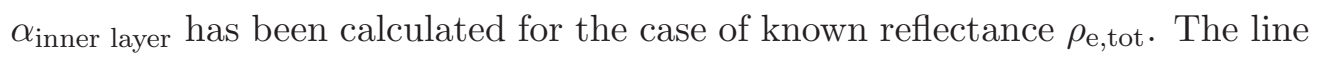
graphs on the right hand side are valid for $\gamma_{\mathrm{f}}=0 \ldots \ldots \ldots \ldots$

11 Angle-dependent solar absorptance $\alpha_{\text {outer layer in the facade for an internal vene- }}$ tian blind with Genius slats in combination with glazing with $g_{\mathrm{gzg}}=0.31$.

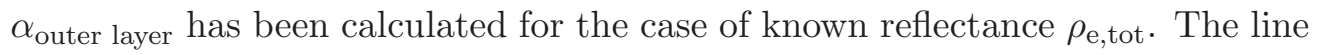
graphs on the right hand side are valid for $\gamma_{\mathrm{f}}=0 \ldots \ldots \ldots$. . . . . . 30 


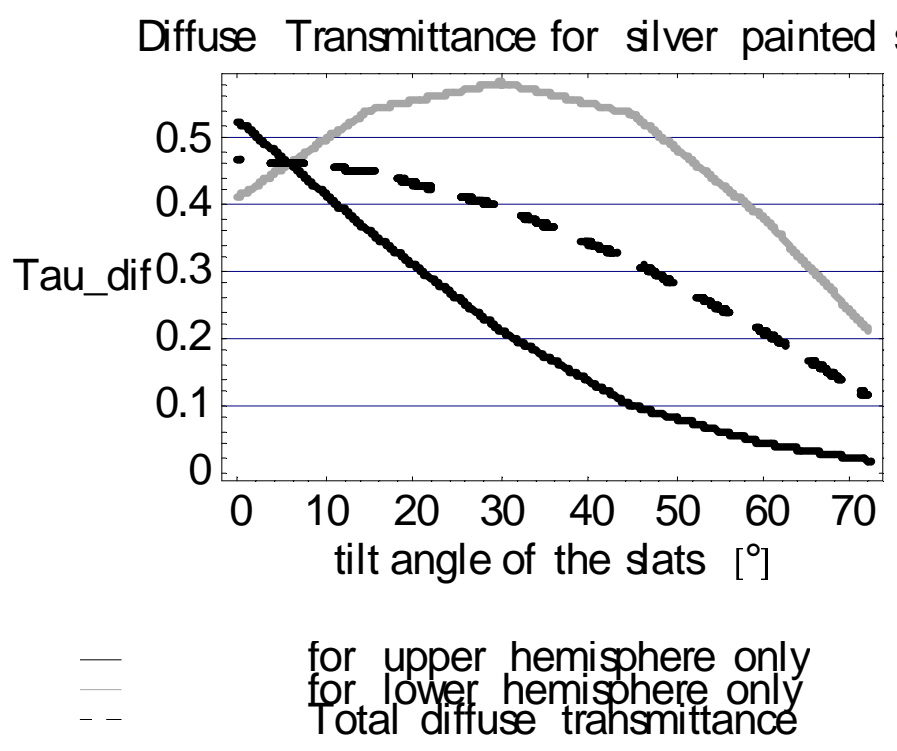

Figure 1: Diffuse transmittance for an external venetian blind with convex (conventionally shaped) slats without glazing. The top surface of the slats is matt silver $\left(\rho_{\mathrm{e}, \text { tot }}=0.59\right)$, the bottom is light grey $\left(\rho_{\mathrm{e}, \mathrm{tot}}=0.58\right)$.

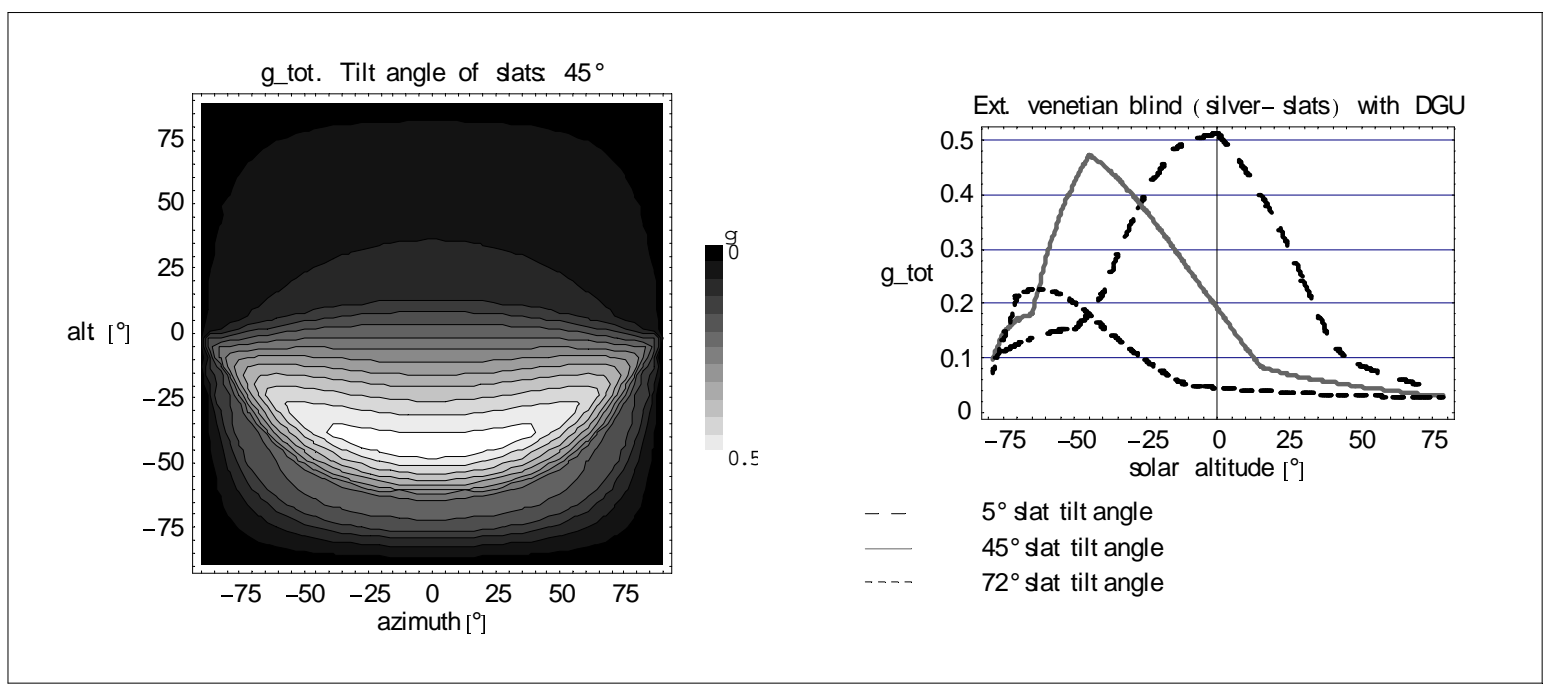

Figure 2: $g$-value for an external, matt silver venetian blind with convex (conventionally shaped) slats in combination with glazing with $g_{\mathrm{gzg}}=0.58$. The line graphs on the right hand side are valid for $\gamma_{f}=0$ 


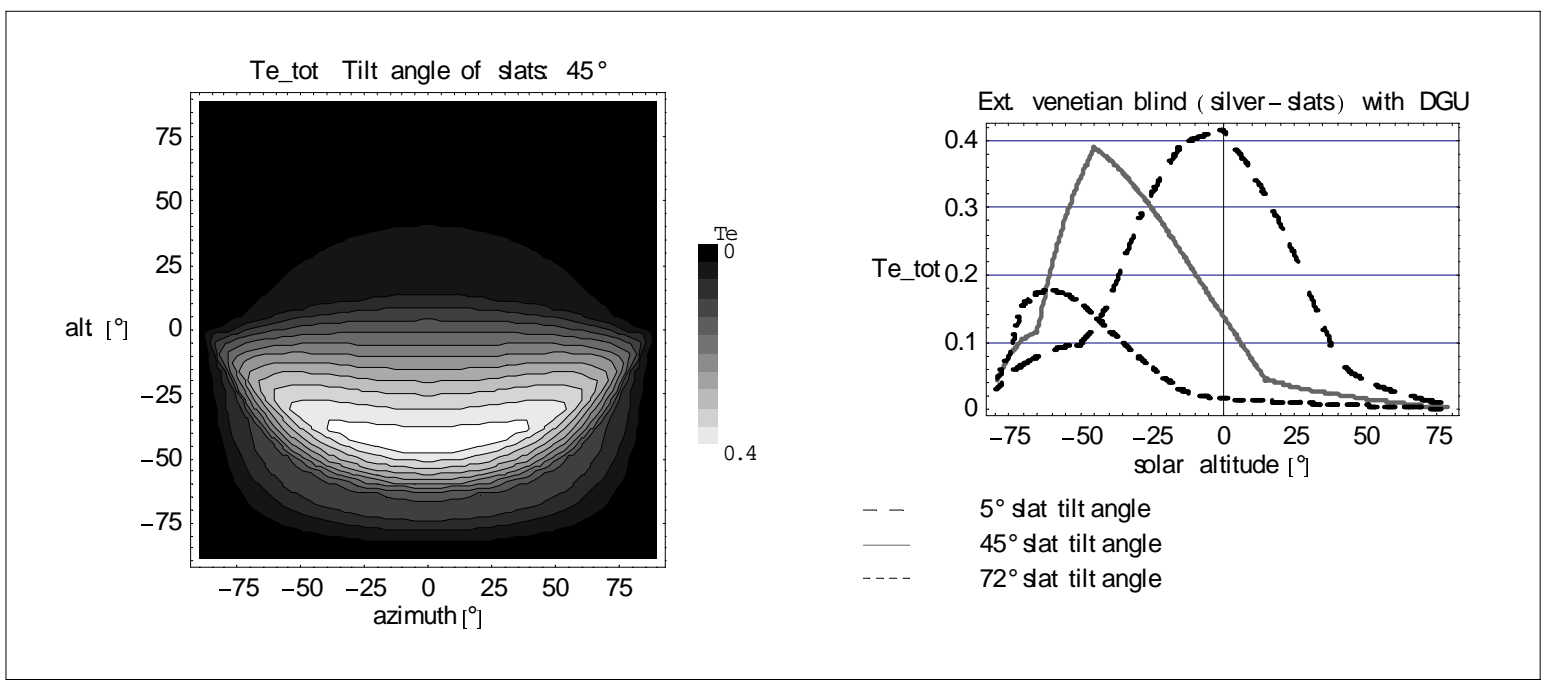

Figure 3: Solar transmittance $\tau_{e}$ for an external, matt silver venetian blind with convex (conventionally shaped) slats in combination with a glazing with $g_{\mathrm{gzg}}=0.58$. The line graphs on the right hand side are valid for $\gamma_{\mathrm{f}}=0$.

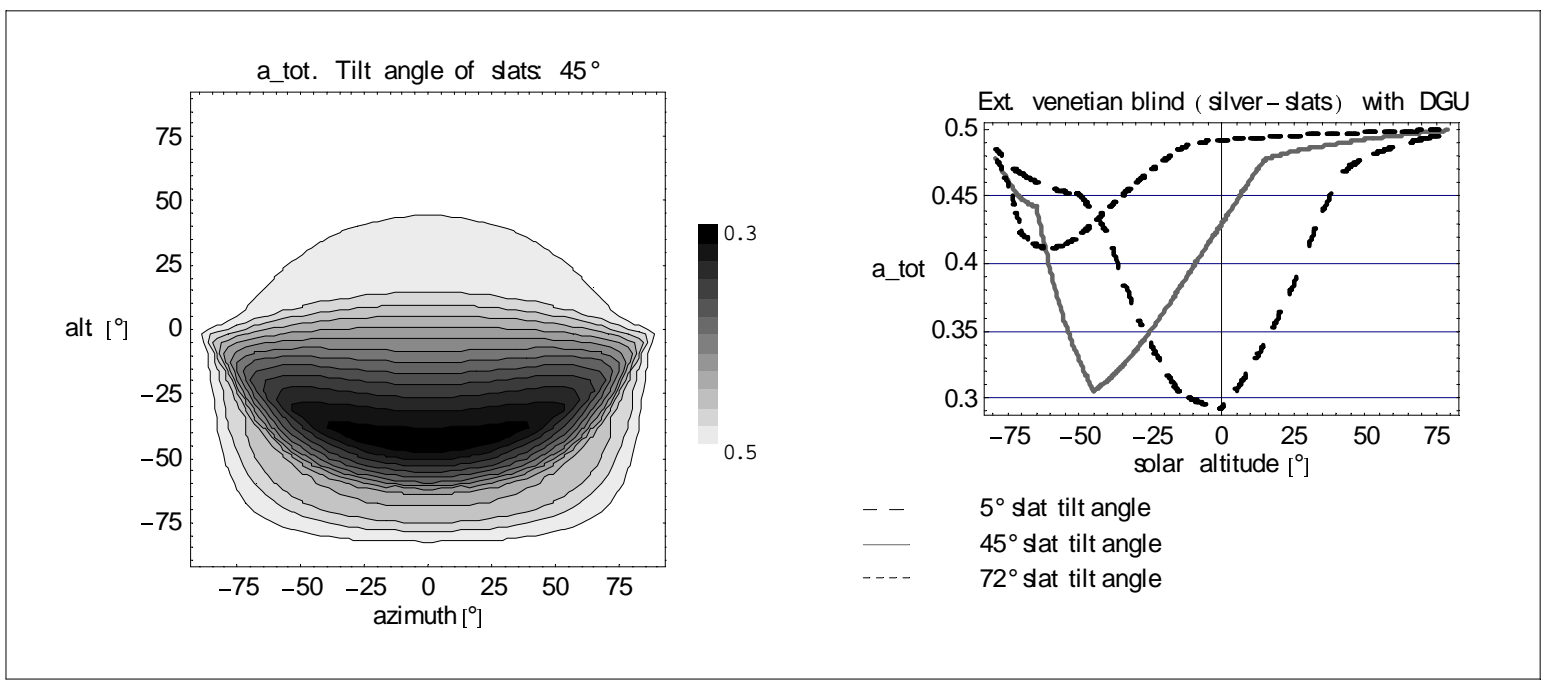

Figure 4: Angle-dependent total solar absorptance $\alpha_{\mathrm{e}, \text { tot }}$ in the facade for an external, matt silver venetian blind with convex (conventionally shaped) slats in combination with glazing with $g_{\mathrm{gzg}}=0.58$. $\alpha_{\mathrm{e}, \text { tot }}$ has been calculated for the special case of unknown reflectance $\rho_{\mathrm{e}, \mathrm{tot}}$. The line graphs on the right hand side are valid for $\gamma_{\mathrm{f}}=0$. 


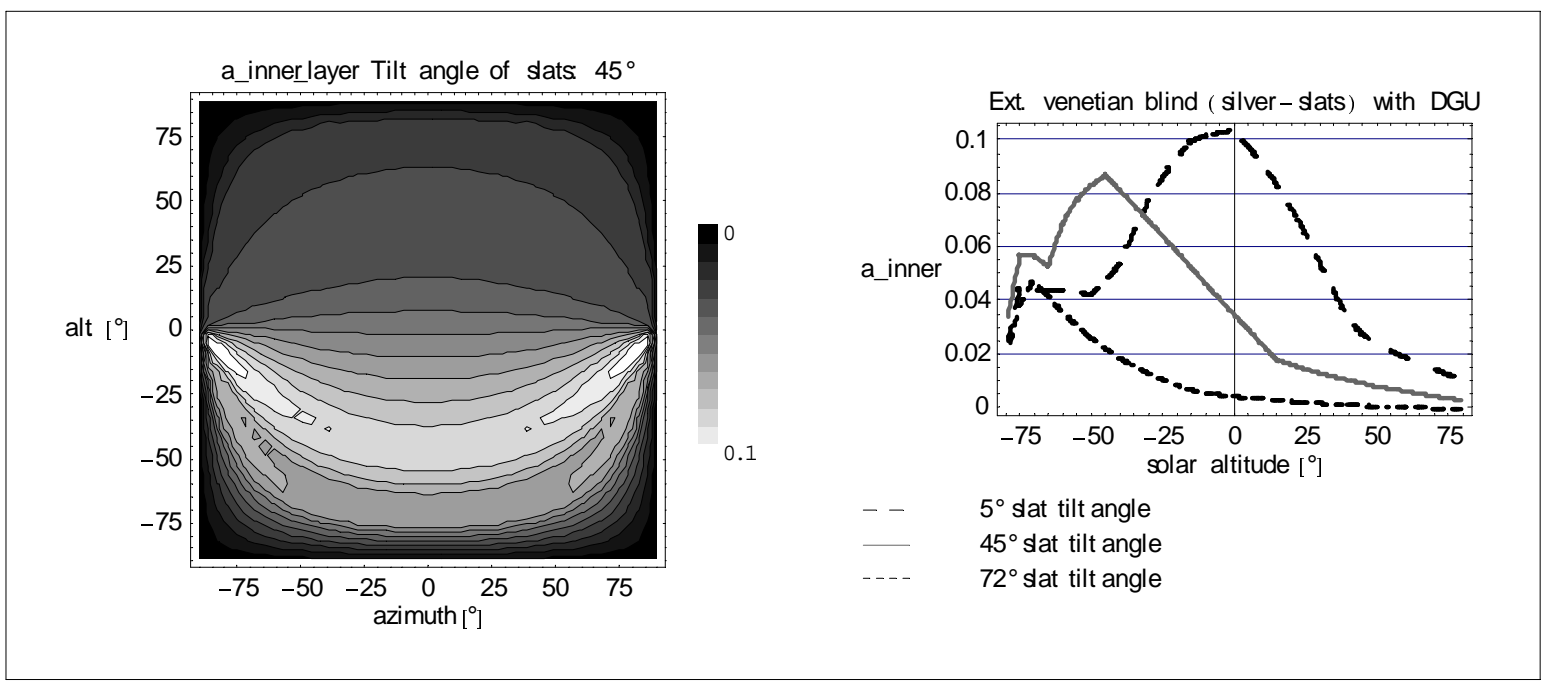

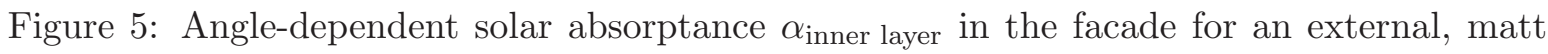
silver venetian blind with convex (conventionally shaped) slats in combination with glazing

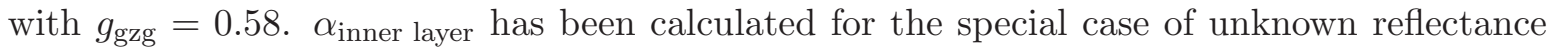
$\rho_{\mathrm{e}, \text { tot. }}$ The line graphs on the right hand side are valid for $\gamma_{\mathrm{f}}=0$.

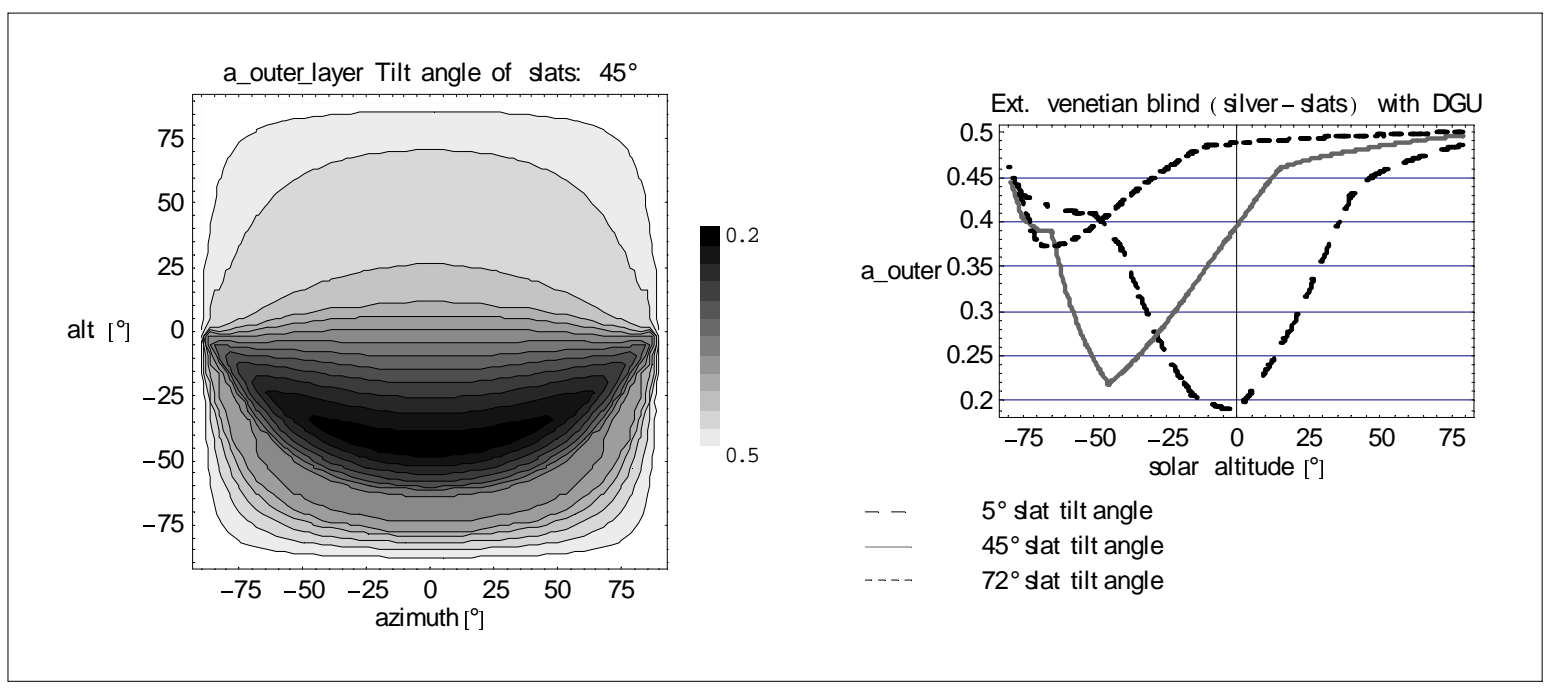

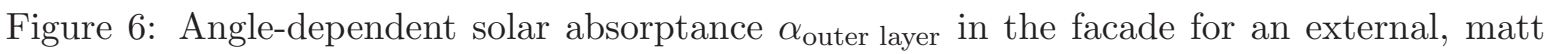
silver venetian blind with convex (conventionally shaped) slats in combination with glazing

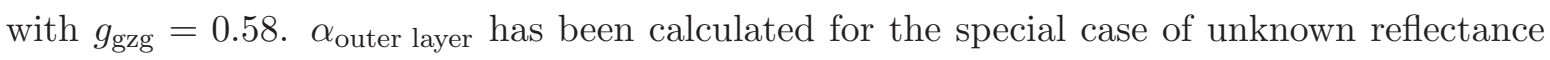
$\rho_{\mathrm{e}, \mathrm{tot}}$. The line graphs on the right hand side are valid for $\gamma_{\mathrm{f}}=0$. 


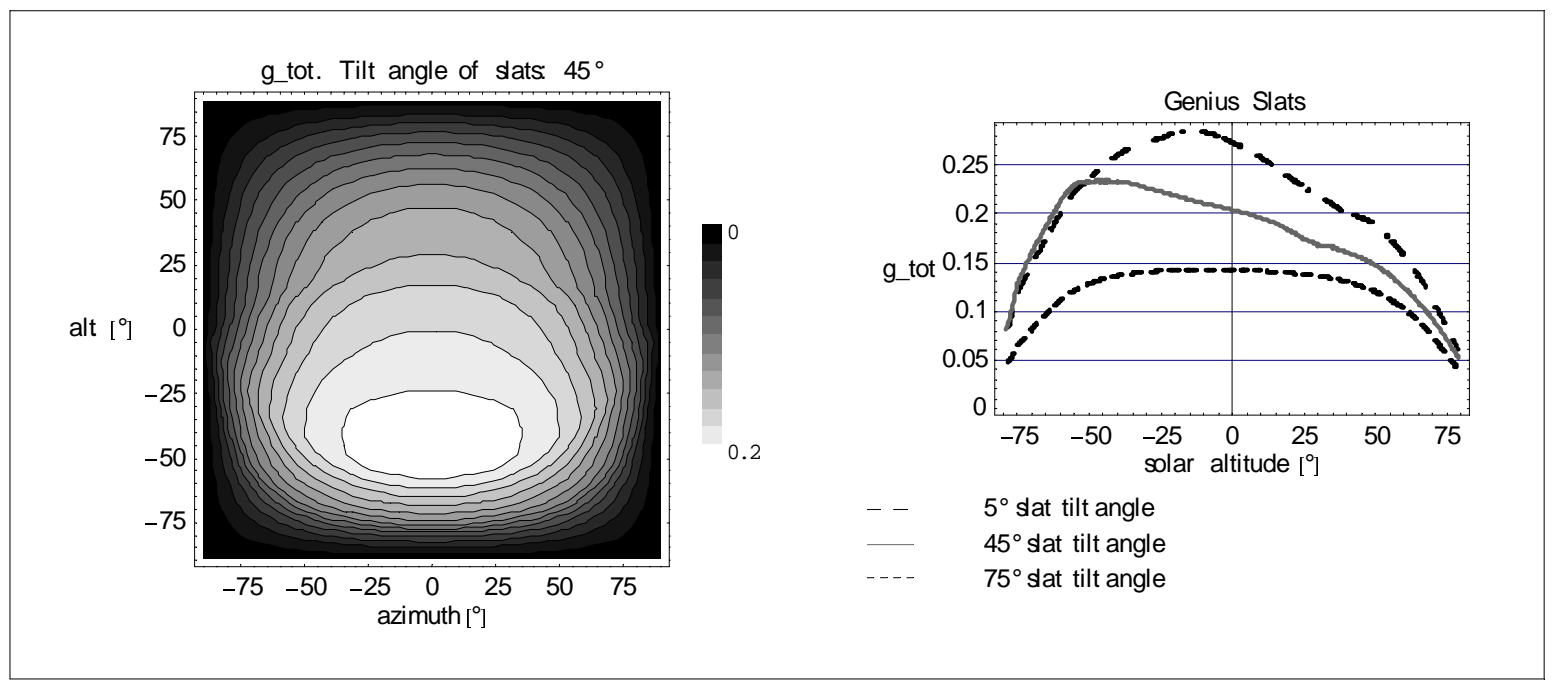

Figure 7: $g$-value for an internal venetian blind with Genius slats in combination with glazing with $g_{\mathrm{gzg}}=0.31$. The line graphs on the right hand side are valid for $\gamma_{f}=0$.

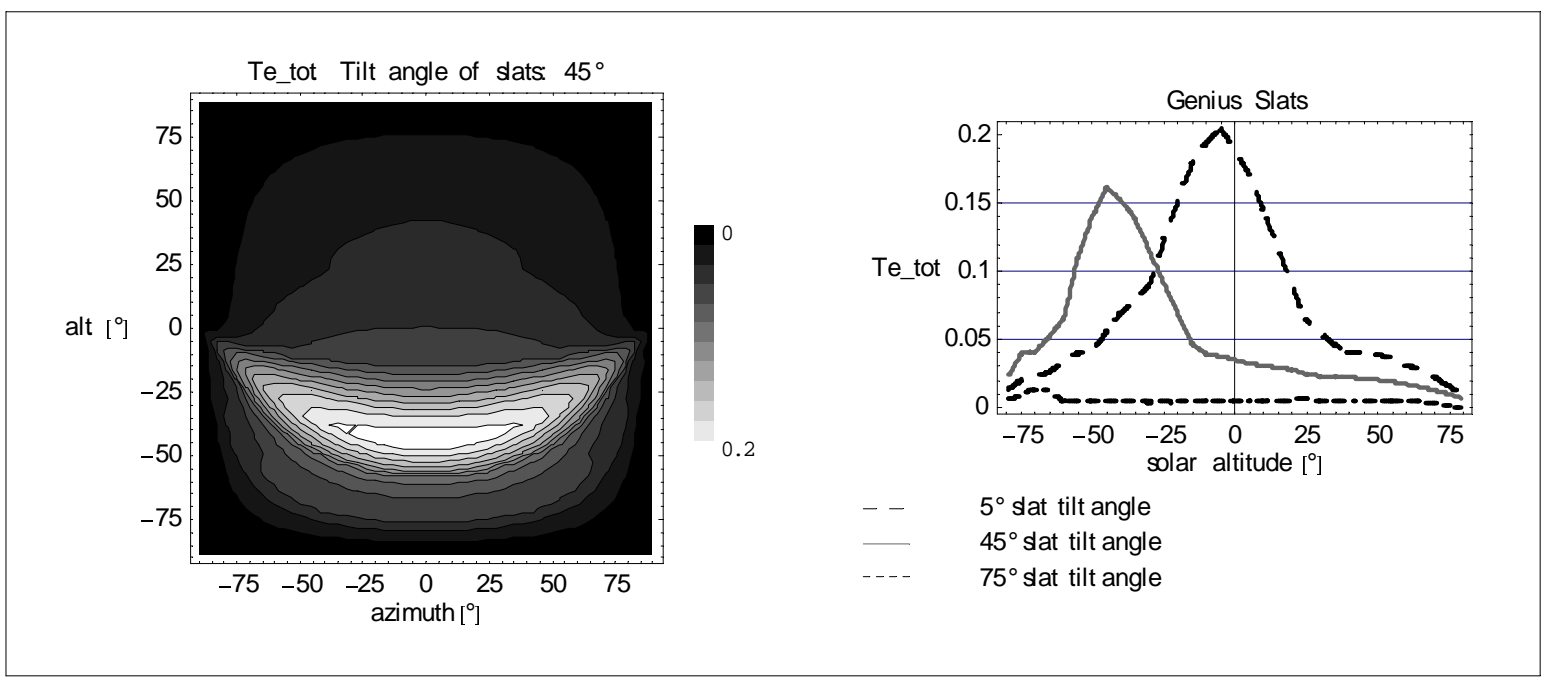

Figure 8: Solar transmittance $\tau_{e}$ for an internal venetian blind with Genius slats in combination with glazing with $g_{\mathrm{gzg}}=0.31$. The line graphs on the right hand side are valid for $\gamma_{\mathrm{f}}=0$. 


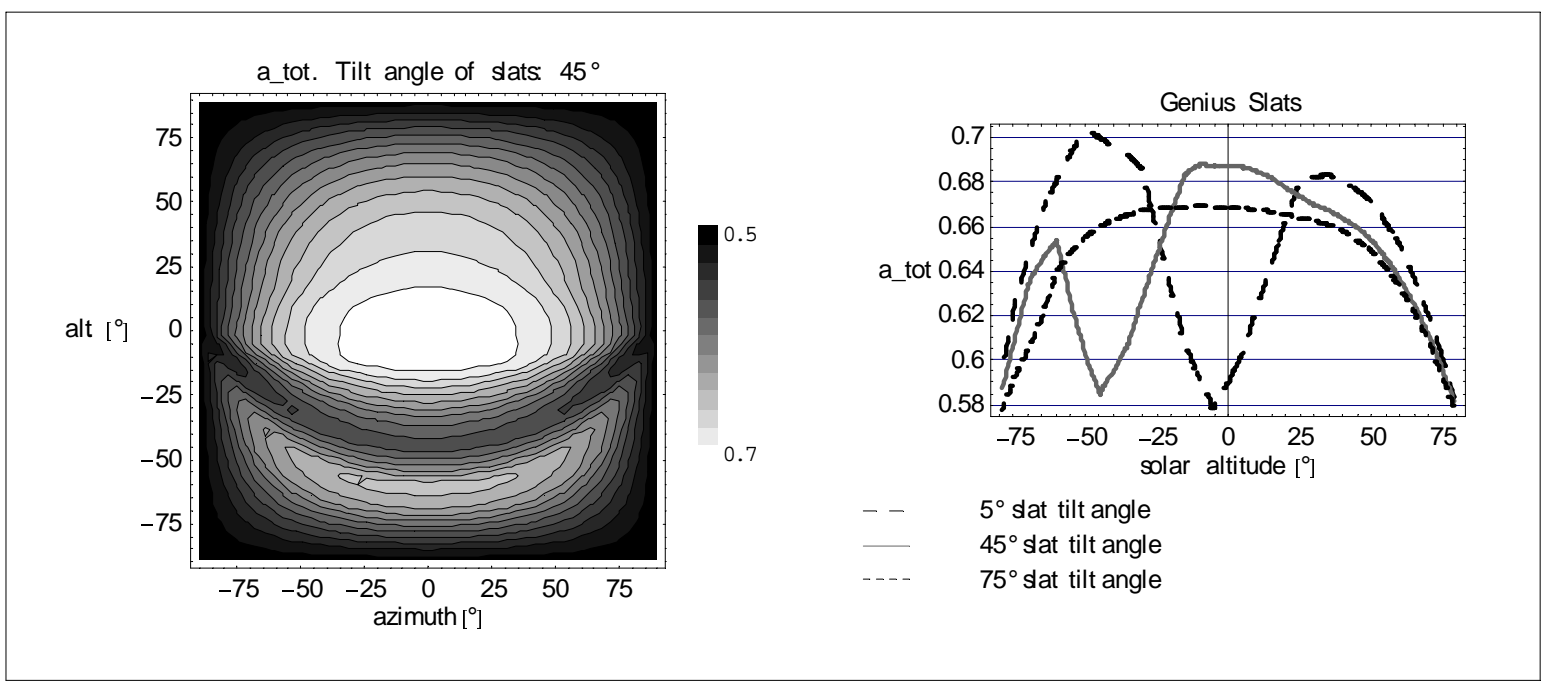

Figure 9: Angle-dependent total solar absorptance $\alpha_{\mathrm{e}, \text { tot }}$ in the facade for an internal venetian blind with Genius slats in combination with glazing with $g_{\mathrm{gzg}}=0.31 . \alpha_{\mathrm{e}, \text { tot }}$ has been calculated for the case of known reflectance $\rho_{\mathrm{e}, \mathrm{tot}}$. The line graphs on the right hand side are valid for $\gamma_{\mathrm{f}}=0$.
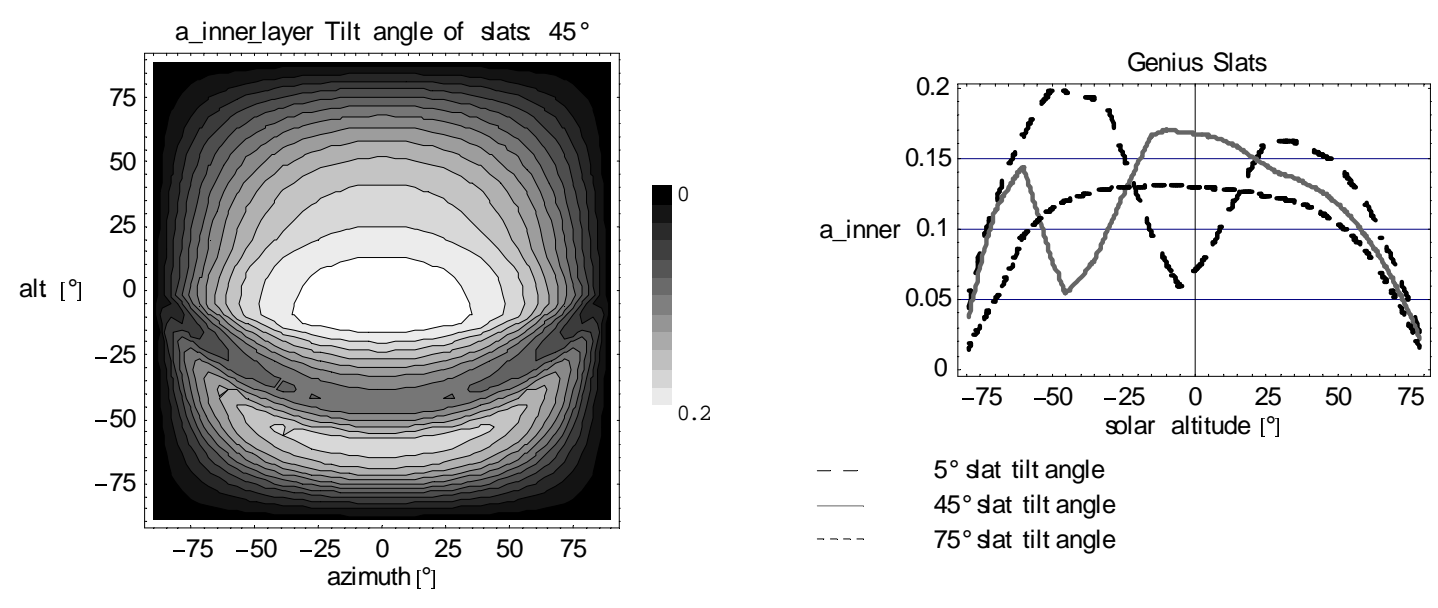

$\quad-\quad 5^{\circ}$ sat tilt angle

$45^{\circ}$ sat tilt angle

$75^{\circ}$ sat tilt angle

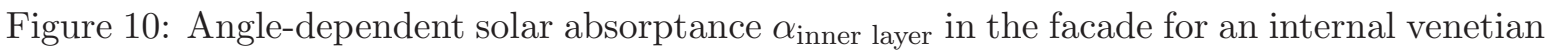
blind with Genius slats in combination with glazing with $g_{\mathrm{gzg}}=0.31$. $\alpha_{\text {inner layer }}$ has been calculated for the case of known reflectance $\rho_{\mathrm{e}, \text { tot }}$. The line graphs on the right hand side are valid for $\gamma_{\mathrm{f}}=0$. 


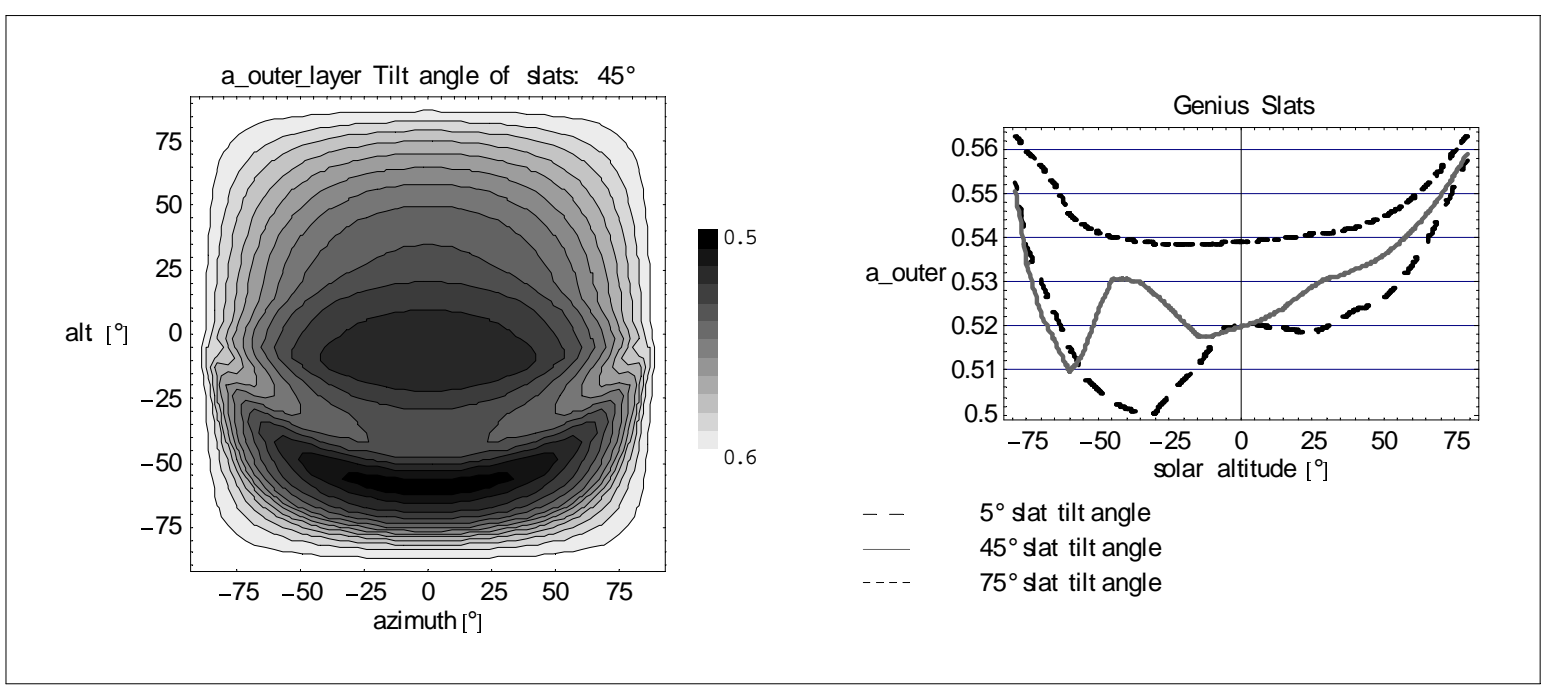

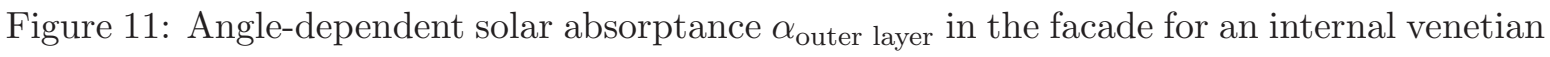
blind with Genius slats in combination with glazing with $g_{\mathrm{gzg}}=0.31$. $\alpha_{\text {outer layer }}$ has been calculated for the case of known reflectance $\rho_{\mathrm{e}, \mathrm{tot}}$. The line graphs on the right hand side are valid for $\gamma_{\mathrm{f}}=0$. 